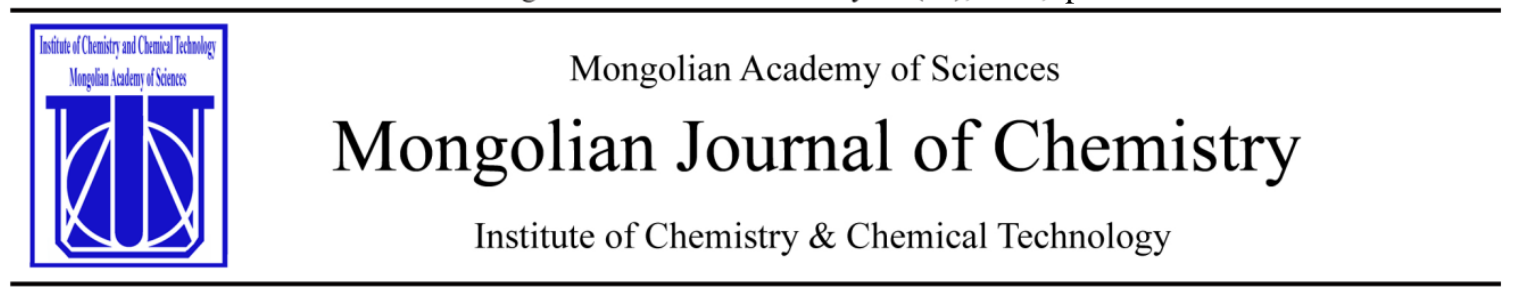

\title{
Chemical and biological investigation of the Agaricus silvaticus Schaeff ex. Secr
}

\author{
L.Munkhgerel $^{1}$, N.Erdenechimeg ${ }^{1}$, M.Dumaa ${ }^{1}$, G.Zhang $^{2}$, P.Odonmajig $^{1}$, D.Regdel $^{1}$ \\ ${ }^{1}$ Institute of Chemistry and Chemical Technology, MAS, Mongolia \\ ${ }^{2}$ Chengdu Institute of Biology, CAS, China
}

\begin{abstract}
Extract of Agaricus silvaticus Schaeff ex. Secr fungus have been known to have biological activities, including antibacterial, antiviral, anticancer, antioxidant, anticomplementary and immunostimulating effects. In this study we first time identified that Agaricus silvaticus Schaeff ex. Secr has interferon like activity. We first time isolated the four known compounds such as, mannitol (1), urea (2), ergosterol (3) and ergosterol peroxide (4) from 95\% ethanol extracts of Agaricus silvaticus Schaeff ex. Secr in Mongolia. Their structures were elucidated on the basis of extensive analysis of spectral data and by comparison with authentic samples.
\end{abstract}

Keywords: Agaricus silvaticus Schaeff ex. Secr., A.silvaticus, A.sylvaticus, IFN-like activity, luciferase, mannitol,

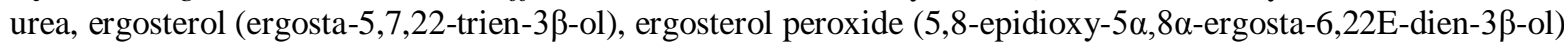

\section{Introduction}

$\mathrm{M}$ ushrooms are considered nutraceuticals or functional foods by many clinicians and researchers, a fact that has also stimulated the search by Brazilian producers for more advanced production techniques along with introduction of new species. According to Urben, there is great genetic variety of native Agaricus genus mushrooms cultivated throughout the world [1].

Agaricus is a large and important genus of mushroom containing both edible and poisonous species, with possibly over 300 members worldwide. This genus belongs to Phylum Basidiomycota, Class Hymenomycetes (newly described Class Agaricomycetes), Order: Agaricales, Family: Agaricaceae [2].

Five Agaricus sp. proved to have antioxidant activity and mushroom extracts revealed similar electrochemical responses, suggesting similar electroactive chemical composition and oxidation potentials more positive than those of the standards (ascorbic and gallic acids). A. silvaticus was the most efficient species presenting the lowest EC values in the chemical and biochemical assays and the highest antioxidant power in the electrochemical assays [3].

Agaricus silvaticus is able to reduce anemia and improve biochemical parameters in animals with cancer and has no adverse effects on the blood cells of healthy animals. Agaricus silvaticus treatment was able to reduce anemia in animals with cancer. Biochemical parameters were nearer the normal levels in animals treated with this mushroom. These results suggest that administration of Agaricus silvaticus Schaeff ex. Secr extract has beneficial effects in rats with Walker 256 tumor, especially in the hematopoietic system [4].

Brazilian researchers have reported that the effects of the dietary supplementation with Agaricus sylvaticus fungus in relation to 
the quality of life in 56 patients with colorectal and gastrointestinal cancer during post-surgery phase. The patients were treated in the randomized study separated as placebocontrolled and Agaricus sylvaticus $(30 \mathrm{mg} / \mathrm{kg} /$ day) supplemented groups. After six months of treatment, it was observed an increase of adhesion to physical activity; improved disposition and good mood, reduction of complaints, pains, and alterations of sleep such as insomnia and bad nights of sleep when A. sylvaticus and placebo groups were compared [5].

All these studies showed that nutritional supplementation with Agaricales fungi have beneficial effects in patients, suggesting that it may consist in a new therapeutic perspective to cancer treatment.

\section{Experimental}

Melting points were determined on an X-6 apparatus (Beijing Fukai Science and Technology Co. Ltd., P. R. China) and are uncorrected. Optical rotations were measured with a Perkin-Elmer 341 automatic polarimeter (Beaconsfield, United Kingdom). Nuclear magnetic resonance (NMR) spectra were recorded on an Avance Bruker 600 spectrometer $\left(600 \mathrm{MHz}\right.$ for ${ }^{1} \mathrm{H}$ NMR and ${ }^{13} \mathrm{C}$ NMR, Bruker Inc., Rhinstetten, Germany) at room temperature. The chemical shifts $(\delta)$ are reported in ppm using tetramethylsilane (TMS) as an internal standard, and the coupling constants $(\mathrm{J})$ are given in Hertz $(\mathrm{Hz})$. High-resolution electrospray ionization mass spectra (HRESIMS) and ESIMS spectra were obtained on a Bruker Bio TOF IIIQ mass spectrometer. Column chromatography (CC) was performed on self-packed open column with silica gel from Qingdao Ocean Chemical Engineering Company (QOCEC, P.R. China). Thin layer chromatography (TLC) analyses were carried out on plates precoated with 10$40 \mu \mathrm{m}$ of silica gel GF254 from QOCEC and detected under a UV lamp at 254 or $365 \mathrm{~nm}$ and visualized by spraying $8 \%$ phosphomolybdic acid-ethanol solution $(\mathrm{w} / \mathrm{v}), 5 \%$ sulfuric acid (w/v) and 10\% ninhydrine- n-butanol (w/v) followed by heating, or visualized by iodine [6].

\section{Mushroom material}

The whole mushrooms of Agaricus silvaticus Schaeff ex. Secr were collected from Bayantes soum, Zavkhan province, Mongolia, in 2009. The mushroom sample was identified by researcher B.Burenbaatar and N.Kherlenchimeg of Institute of Botany, Mongolian Academy of Sciences. A voucher specimen was deposited at the Herbarium of Institute of Botany and Institute of Chemistry and Chemical Technology, MAS.

\section{Extraction and Isolation}

The air dried Agaricus silvaticus Schaeff ex. Secr (900g) was extracted with 95\% ethanol at room temperature for 3 times (1 time*7 days), to give ethanol extract, filtered and concentrated to yield the ethanol extract As3 (71g). The crude ethanol extract was suspended methanol with methanol soluble As3A (61g) and methanol insoluble As3B (18mg) to give into two sub- fractions. The methanol soluble extract (As3A) was suspended in water and subjected to column chromatography with resin D101 and eluted $\mathrm{H}_{2} \mathrm{O}, 10 \%, 30 \%, 50 \%, 70 \%$ and $95 \%$ ethanol to give into 6 sub-fractions.

The ethanol soluble fraction was recrystallized to yield compound $\mathbf{1}$ (AaI $55 \mathrm{mg})$. A5 (5.12g) sub fraction was subjected to column chromatography with silica gel (200-300 mesh) and eluted using mixture of petroleum: acetone: acetic acid (5:1:0.1), chloroform:methanol (20:1 to 0:1) solvents, to afforded As3A5A and As3A5B into 2 subfractions. As3A5B 63-69 were recrystallized to yield compound 2 (As3A5BT 8mg) from fraction 130-140.

A6 (5.8g) was subjected to column chromatography with silica gel (200-300 mesh) and eluted using a stepwise gradient of petroleum and acetone (20:1 to $0: 1)$, of chloroform and methanol $(10: 1$ to $0: 1)$ to afford 560 sub-fractions. Fractions 141 and 229 were chromatographed on silica gel column using petroleum: acetone (20:1) solvents, giving compounds 3 (As3A6Da 20mg). Fractions 273-343 were rechromatographed on silica gel column (sil 60 mesh) with Pe: Ace (gradient) as the solvent system, giving compounds $\mathbf{4}$ (As3A6Ea 8mg). 
Interferon-like activity The IFN-like activity was determined by Luciferase Reporter Assay System according to the manufacturer's instruction (Promega), using Thermo Scientific Varioskan ${ }^{\circledR}$ Flash. The extracts library were dissolved in DMSO to a final concentration of $100 \mathrm{mg} / \mathrm{mL}$ and stored at $-20{ }^{\circ} \mathrm{C}$ until use. Working solution was prepared in RPMI 1640 medium at a final concentration $100 \mu \mathrm{g} / \mathrm{mL}$ in the plate.

Cell line: The human hepatocellular carcinoma HepG2 cell line was obtained from ATCC, and was maintained in RPMI-1640 (GIBCO, Thermo) medium supplemented with $10 \%(\mathrm{v} / \mathrm{v})$ calf serum and antibiotics $(100 \mathrm{U} / \mathrm{ml}$ penicillin and $0.1 \mathrm{~g} / \mathrm{L}$ streptomycin) at $37{ }^{\circ} \mathrm{C}$ in the presence of $5 \%$ CO2. The HepG2-ISRE-Luc2 firefly Luciferase reporter cells was generated by transfecting the HepG2 cells with pISRE-Luc plasmid.

Luciferase Assay for screening: Screen was performed at 96 well format, for each plate, 16 wells were used for negative and positive control, the remaining 80 wells contained test samples which were diluted to $100 \mu \mathrm{g} / \mathrm{ml}$. HepG2-ISRE-Luc2 cells were plated at $5 \times 10^{4}$ cells/well in 96 -well plates. After incubation for $24 \mathrm{~h}$ at $37^{\circ} \mathrm{C}$ in $5 \% \mathrm{CO}_{2}$, cells were stimulated with test samples and 200IU IFN- $\alpha$ as positive control for $24 \mathrm{~h}$. Cells were lysed in Reporter Lysis Buffer and luciferase activity was measured by Luciferase Reporter Assay System according to the manufacturer's instruction (Promega), using Thermo Scientific Varioskan ${ }^{\circledR}$ Flash [7].

\section{Results and Discussion}

As seen from biological studies, A2, A3, A4 groups of A.silvaticus extract have showed relatively high interferon identical activities than A5 and A6, while water extract (A1) and methanol non-dissolved part (As3B) did not show those activities, respectively (Fig.1).

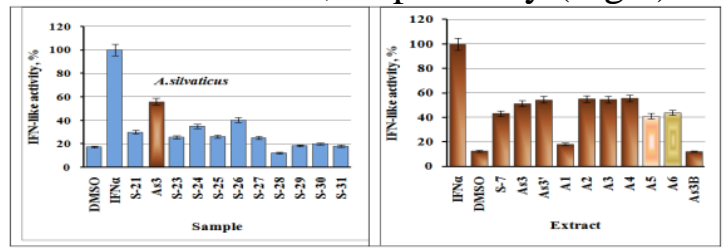

Fig.1. IFN-like activity extracts of Agaricus silvaticus Schaeff ex. Secr
Activities of A2, A3, A4 groups of Agaricus silvaticus Schaeff ex. Secr extract were similar to alfa-interferon, which was used as a control, so it was considered that those extracts have some compounds identical to interferon in high amount.

Highly active A2, A3, A4 group of extracts did not show any spot and picks by TLC and HPLC, where there are no necessities to additional study or change of methodology; therefore, phytochemistry study was performed in A5 and A6 extracts separating them by column chromatography.

The four isolated compounds, mannitol (1), urea (2), ergosterol (3) and ergosterol peroxide (4) were identified in comparison with EI-MS, ${ }^{1} \mathrm{H}-\mathrm{NMR}$ and ${ }^{13} \mathrm{C}-\mathrm{NMR}$ spectral data of published earlier.

Compound 1 (AaI) was isolated as an amorphous powder and its elemental composition was determined to $\mathrm{C}_{6} \mathrm{H}_{14} \mathrm{O}_{6}$ by ESI-MS. AaI which was isolated from the ethanol extract was believed to be a monosaccharide based on ${ }^{1} \mathrm{HNMR}$ measurement and its polarity. ${ }^{1} \mathrm{H}$ NMR peaks were observed between $\delta 3.59,3.71$ to 3.79 and only three carbons at $\delta 70.8,69.3$, and 63.2 were evident in the ${ }^{13} \mathrm{C}$ NMR spectrum (Fig.2). Based on an extensive literature search, this compound was believed to be mannitol. In addition, the ${ }^{1} \mathrm{H}$ and ${ }^{13} \mathrm{C}$ NMR spectra of compound AaI were in good agreement with those of mannitol. Therefore, compound AaI was identified as mannitol [8].

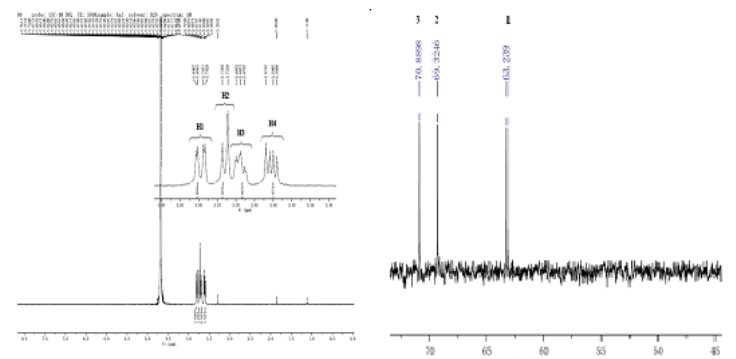

Fig. 2. ${ }^{1} \mathrm{H}$ and ${ }^{13} \mathrm{C}$ NMR spectral data of mannitol (1)

Urea (2) and ergosterol (3) structures were elucidated on the basis of extensive analysis of spectral data and by comparison with authentic samples [9].

Compound (4) was isolated as a colorless crystals and its elemental composition was determined to be $\mathrm{C}_{28} \mathrm{H}_{44} \mathrm{O}_{3} \quad$ ESI-MS. Ergosterol peroxide (5,8-epidioxy- $5 \alpha, 8 \alpha$ - 
ergosta-6,22E-dien-3 $\beta$-ol) seemed to have an ergosterol (ergosta-5,7,22-trien-3 $\beta$-ol) type steroid structure by comparing its NMR spectral data with those of ergosterol (3).
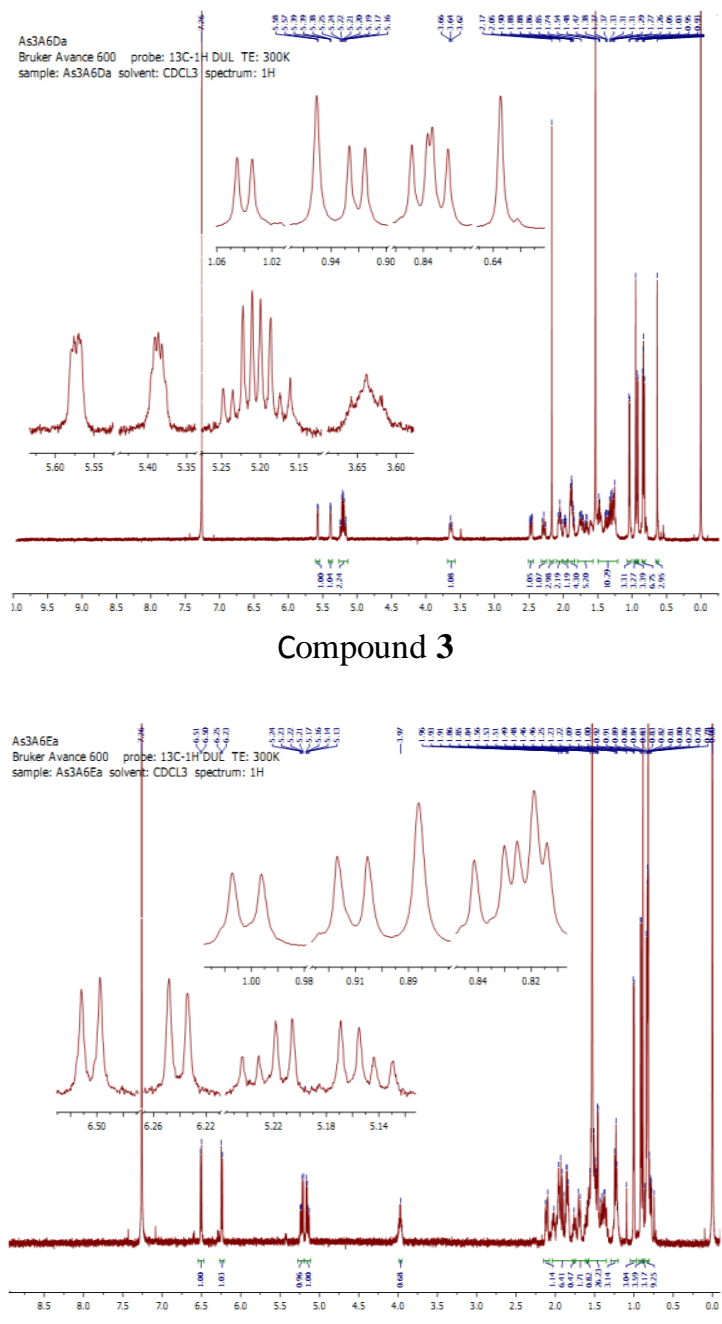

Compound 4

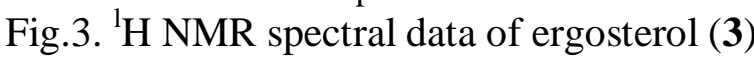
and ergosterol peroxide (4)

The difference in molecular formula between ergosterol (3) and compound $\mathbf{4}$ is two oxygens, implying that compound $\mathbf{4}$ is a peroxidated derivative of ergosterol (3). From the ${ }^{1} \mathrm{H}$ and ${ }^{13} \mathrm{C}$ NMR spectral data, compound 4 was identified as ergosterol peroxide (Table 1). The ${ }^{13} \mathrm{C}$ NMR spectrum showed carbon signals of two double bonds at $\delta 130.68(\mathrm{C}-7), \delta 132.26$ (C-23), $\delta 135.16$ (C$22), \delta 135.39$ (C-6). Other characteristic signals in ${ }^{1} \mathrm{H}$ NMR spectrum were $\delta 5.183$ $(\mathrm{m}, 2 \mathrm{H}, \mathrm{H}-22, \mathrm{H}-23), \delta 3.961(\mathrm{~m}, 1 \mathrm{H},-\mathrm{OH}), \delta$ $0.998(\mathrm{~d}, \mathrm{~J}=6,3 \mathrm{H}, \mathrm{H}-21), \delta 0.908(\mathrm{~d}, \mathrm{~J}=7$, $3 \mathrm{H}, \mathrm{H}-28), \delta 0.881$ (s, 3H, H-19), $\delta 0.831$ (d, $\mathrm{J}=8,3 \mathrm{H}, \mathrm{H}-27), \delta 0.818(\mathrm{~d}, \mathrm{~J}=8.5,3 \mathrm{H}, \mathrm{H}-$ $26)$, and $\delta 0.815$ (s, 3H, H-18) [9, 10].
Table 1. ${ }^{\mathrm{l} H}$ NMR spectral data of ergosterol (3) and ergosterol peroxide (4)

\begin{tabular}{|c|c|c|c|}
\hline $\begin{array}{c}{ }^{1} \mathbf{H} \\
\text { (Shin Yusoo } \\
\text { et al) } \\
\end{array}$ & A6Ea & $\begin{array}{c}{ }^{1} \text { H NMR } \\
(\text { S.Kim et } \\
\text { all }) \\
\end{array}$ & A6Da \\
\hline $3.96, \mathrm{~m}$ & $3.97, \mathrm{~m}, 1 \mathrm{H},-\mathrm{OH}$ & $3.633, \mathrm{~m}$ & $3.64, \mathrm{~m},(\mathrm{H}-3)$ \\
\hline $6.24, \mathrm{~d}, \mathrm{~J}=8$ & $6.24, \mathrm{~d}, \mathrm{H}-6$ & $\begin{array}{c}5.577,5.389, \\
\mathrm{~J}=2.358\end{array}$ & $5.577,5.389$ \\
\hline $6.51, \mathrm{~d}, \mathrm{~J}=8.6$ & $6.50, \mathrm{~d}, \mathrm{H}-7$ & $\begin{array}{c}5.181,5.122, \\
\mathrm{~J}=2.358\end{array}$ & $5.181,5.122$ \\
\hline $0.82, \mathrm{~s}$ & $0.83, \mathrm{~s}, 3 \mathrm{H}, \mathrm{H}-18$ & $0.633, \mathrm{~s}$ & $0.63, \mathrm{~s},(\mathrm{H}-18)$ \\
\hline $0.88, \mathrm{~s}$ & $0.89, \mathrm{~s}, 3 \mathrm{H}, \mathrm{H}-19$ & $0.949, \mathrm{~s}$ & $0.95, \mathrm{~s},(\mathrm{H}-19)$ \\
\hline $1.00, \mathrm{~d}, \mathrm{~J}=6.6$ & $1.00, \mathrm{~d}, 3 \mathrm{H}, \mathrm{H}-21$ & & \\
\hline $5.16, \mathrm{~d}, \mathrm{~J}=7.6$ & $5.16, \mathrm{dd}$ & & \\
\hline $5.20, \mathrm{~d}, \mathrm{~J}=6.8$ & $5.22, \mathrm{~d}$, & & \\
\hline $0.82, \mathrm{~d}, \mathrm{~J}=6.7$ & $0.82, \mathrm{~d}, 3 \mathrm{H}, \mathrm{H}-26$ & $\begin{array}{c}1.038, \mathrm{~d}, \\
\mathrm{~J}=6.6\end{array}$ & $1.04, \mathrm{~d},(\mathrm{H}-26)$ \\
\hline $0.84, \mathrm{~d}, \mathrm{~J}=6.7$ & $0.84, \mathrm{~d}, 3 \mathrm{H}, \mathrm{H}-27$ & $\begin{array}{c}0.841, \mathrm{~d}, \\
\mathrm{~J}=6.7\end{array}$ & $0.838 \mathrm{~d},(\mathrm{H}-27)$ \\
\hline $0.91, \mathrm{~d}, \mathrm{~J}=6.9$ & $0.91, \mathrm{~d}, 3 \mathrm{H}, \mathrm{H}-28$ & $\begin{array}{c}0.919, \mathrm{~d}, \\
\mathrm{~J}=6.8\end{array}$ & \\
\hline
\end{tabular}

The all four compounds are first found in Agaricus silvaticus Schaeff ex. Secr in Mongolia. The chemical structure of isolated four compounds is shown in Fig. 4. Ergosterol, a sterol, is the biological precursor to Vitamin D2. It is turned into viosterol by ultraviolet light, and is then converted into ergocalciferol, which is a form of Vitamin D. Ergosterol is a component of fungal cell membranes, serving the same function that cholesterol serves in animal cells. Ergosterol is not found in mammalian cell membranes [11].
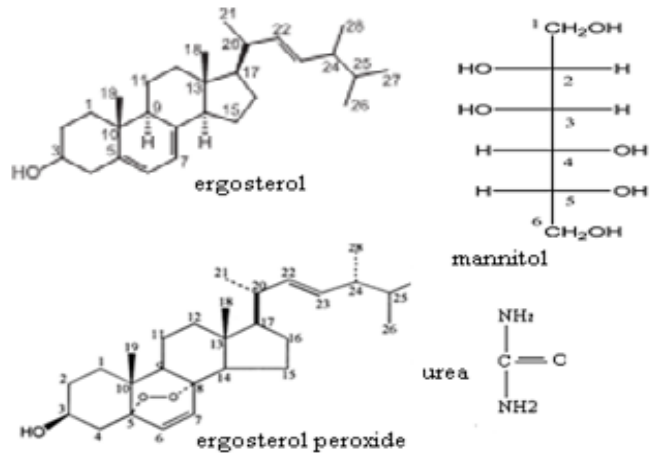

mannitol<smiles>NC(N)=O</smiles>

Fig.4. Structures of the compounds from A.silvaticus

Ergosterol is also used as an indicator of fungal biomass in soil. Though ergosterol does degrade over time, if kept below freezing in a dark environment, this degradation can be slowed or even stopped completely. Research has shown ergosterol may have antitumor properties [12].

Ergosterol peroxide have been previously isolated and identified from Inonotus obliquus, common wood-rotting fungi in Filand, Lanum lyratum and 
Naematoloma fasciculare which is toxic mushroom widely distributed in the world. It was reported that ergosterol peroxide from I.obliquus not only inhibited the growth of cancer cells but also killed them in the antitumor tests. Recent study also revealed its inhibitory effects on induced inflammation and tumor promotion in mouse skin [9].

Based on the summarized results described above, it could be concluded that ergosterol peroxide (4), which is peroxidated at C-5 and C-8 of ergosterol (3), have strong antitumor activity, cytotoxic activity and anticomplementary activity [10].

Ergosterol peroxide (EPO) is a major antitumor sterol produced by edible or medicinal mushrooms. These findings suggest that bacterial metabolites of EPO play a significant role in its cytotoxic activity against human colorectal cancer cells [13].

\section{Conclusions}

- In this study we first time identified that Agaricus silvaticus Schaeff ex. Secr has an interferon like activity.

- Four known compounds such as mannitol (1), urea (2), ergosterol (3) and ergosterol peroxide (4) from fruit bodies of Agaricus silvaticus Schaeff ex. Secr from Mongolia has been isolated successfully. Their structures were elucidated on the basis of extensive analysis of spectral data and by comparison with authentic samples.

- The extraction of chemical compound which has interferon like activity from the natural raw materials is very important as nowadays the cancer and the hepatitis disease increasing highly. Therefore, the findings we demonstrated here is useful for producing the pharmaceuticals to depress the activity of hepatitis B and $\mathrm{C}$ viruses.

\section{Acknowledgements}

We are grateful for financial support from National Natural Science Foundation of China NSFC (2009 20810199) and Mongolian Foundation for Science and Technology.

\section{References}

1. Joice Vinhal Costa, Maria Rita Carvalho Garbi Novaes, Eduardo Ramirez Asquieri., Chemical and Antioxidant Potential of Agaricus sylvaticus Mushroom Grown in Brazil, (2011), J.Bioanal. Biomed 3: 049-054. doi:10.4172/1948593X.1000042

2. Ahmad Mohamad Al-Momany and Gucel Saleh, A Comprehensive Study on Agaricus Species of North Cyprus, (2009), World J. Agric. Sci., V5 (2), P. 195-200

3. L.Barros, S.Falcão, P.Baptista, C.Freire, M.Vilas-Boas. Antioxidant activity of Agaricus sp. mushrooms by chemical, biochemical and electrochemical assays (2008), Food Chemistry, V.111, P.61-66

4. Fortes RC, Recova VC, Melo AL, Novaes MRCG. Quality of life of patients with colorectal cancer on dietary supplementation with Agaricus Sylvaticus fungus: after six months of segment: randomized and placebocontrolled clinical trial. Rev Bras Coloproct. (2007), V.27(2), P.130-138

5. Vanessa Cunha Taveira, Maria Rita Carvalho Garbi Novaes, Marcelo dos Anjos Reis, and Monique Fernandes da Silva, Hematologic and Metabolic Effects of Dietary Supplementation with Agaricus sylvaticus Fungi on Rats Bearing Solid Walker 256 Tumor, (2008), Exp. Biol. Med. V.233, P.1341-1347

6. J.Zhao, M.Zhou, Y.Liu, G.Zhang, Y.Luo, Chromones and coumarins from the dried fructus of Cnidium, (2011), Fitoterapia (in press)

7. C.Li, H.Yua, X.Chena, X.Wua, G.Li, G.Zhang. Three new eudesmanolactones

(1/4eudesmanolides) from Camchaya loloana (2011), Helvetica Chimica Acta,V.94, P.105-110

8. Y.Sook Kim, In-Kyoung Lee, Soon-Ja Seok, Bong-Sik Yun. Chemical Constituents of the fruiting bodies of Clitocybe nebularis and their 
antifungal activity, (2008), Mycobiology, V.36(2) P. 110-113

9. S.Kim, S.Park, T.Min, K.Yu, Antioxidant activity of ergosterol peroxide $(5,8$-Epidioxy- $5 \alpha, 8 \alpha$-ergosta6,22E-dien-3 $\beta$-ol) in Armillariella mellea (1999), Bull. Korean Chem. Soc., V. 20(7), P. 819-823

10. Shin Yusoo, Tamai Yutaka, Terazawa Minoru, Chemical Constituents of Inonotus ohliquus (2001), Eurasian J. For. Res., V2, P.27-30

11. Maria Rita Carvalho Garbi Novaes. Pharmacological effects of Agaricales fungi (2007), Rev. Ciênc. Méd., Campinas, V.16(2), P.87-95J.
12. Takaku T, Kimura Y, Okuda H, Isolation of an antitumor compound from Agaricus blazei Murill and its mechanism of action (2001), J.Nutr., V 131(5), P.1409-1413

13. Joo-Sang Lee, Chao-Mei Ma, DongKi Park, Yasuharu Yoshimi, Minoru Hatanaka and Masao Hattori, Transformation of Ergosterol Peroxide to Cytotoxic Substances by Rat Intestinal Bacteria, (2008), Biol. Pharm. Bull., Vol. 31, P.949-954 . 